\title{
The Application and Analysis of Opera Costume Elements in the Modern Costume Design
}

\author{
Zhang Jinbin \\ International Design Art College, Inner Mongolia Normal University. \\ Hohhot, Inner Mongolia, 010022, China
}

\begin{abstract}
This paper analyzes the application of opera costume elements in modern costume design, combines with the application of ideas in the paper, and applies opera costume elements to modern costume. Under this concept, four kinds of modern ready-to-wear clothes with opera costume elements are designed. Taking the works as examples, the whole process of the application design of opera costume elements in modern costume design is presented, which provides ideas and directions for the modern application design of opera costume elements in the future. It is also hoped that the research findings of this paper can give reference to designers.
\end{abstract}

\section{An Analysis of the Application Design Ideas of Traditional Opera Costume Elements in Modern Costume Design}

With Chinese national attention to its traditional culture, people from all walks of life pay more attention to its protection and inheritance, and clothing industry is no exception. Opera is an important part of Chinese traditional culture. If cultural elements can be used into fashion design, works made by designers will receive unexpected effects, which not only have aesthetic characteristics, but Chinese traditional culture can be inherited in a new way.

\subsection{The Extraction and Application of the Style Elements of Opera Costume}

Traditional Chinese opera costumes are diversified in modelings with excellent styles, fabrics, colors and patterns. As a result, opera costumes have become one of the design materials favored by modern fashion designers. As shown in Figure 1, the designer designs the work inspired from the opera "Peony Pavilion" (A play written by Tang Xianzu, a dramatist of the Ming Dynasty) with the theme of "Dream in the Deserted Garden". In the dream, "Regardless of her parents' detention, Du Liniang (the heroine of the Peony Pavilion) bravely rushed out of her boudoir and went to the garden with Chunxiang (Du's servant girl) to enjoy the scenery of spring. Du Liniang longs for love and she dreams of meeting a Xiucai (Xiucai, one who passed the imperial examination at the county level in the Ming and Qing dynasties) in front of the Peony Pavilion." The story is the starting point for the design. The designer chooses the split fishtail dress style to highlight the identity and status of Du Liniang, and at the same time, emphasizes her unusual act of rushing out of her boudoir to visit the garden. The design elements are from the collar type, the decoration, the layout and position of the pattern in the opera costume, and then those elements are combined with the design of modern dress style to reflect Du Liniang's shyness when she first dreamed about Xiucai. As shown in Figure 2, the theme design of Peking Opera costumes, the designer extracts the typical visual elements of opera costume style in "Mu Guiying Command" (a Peking opera) which are shawl and tassels (from design work 1, and design work 2), integrates them into the modern clothing, and designs the length of the coat according to the "Mang Pao" (a costume of Peking Opera that embroidered Python pattern) (design work 2). The two sets of costume design works collide with each other, sending out a strong cultural atmosphere of Peking Opera and a sense of modern fashion, which makes the costume of Peking Opera show great value that can be explored. 


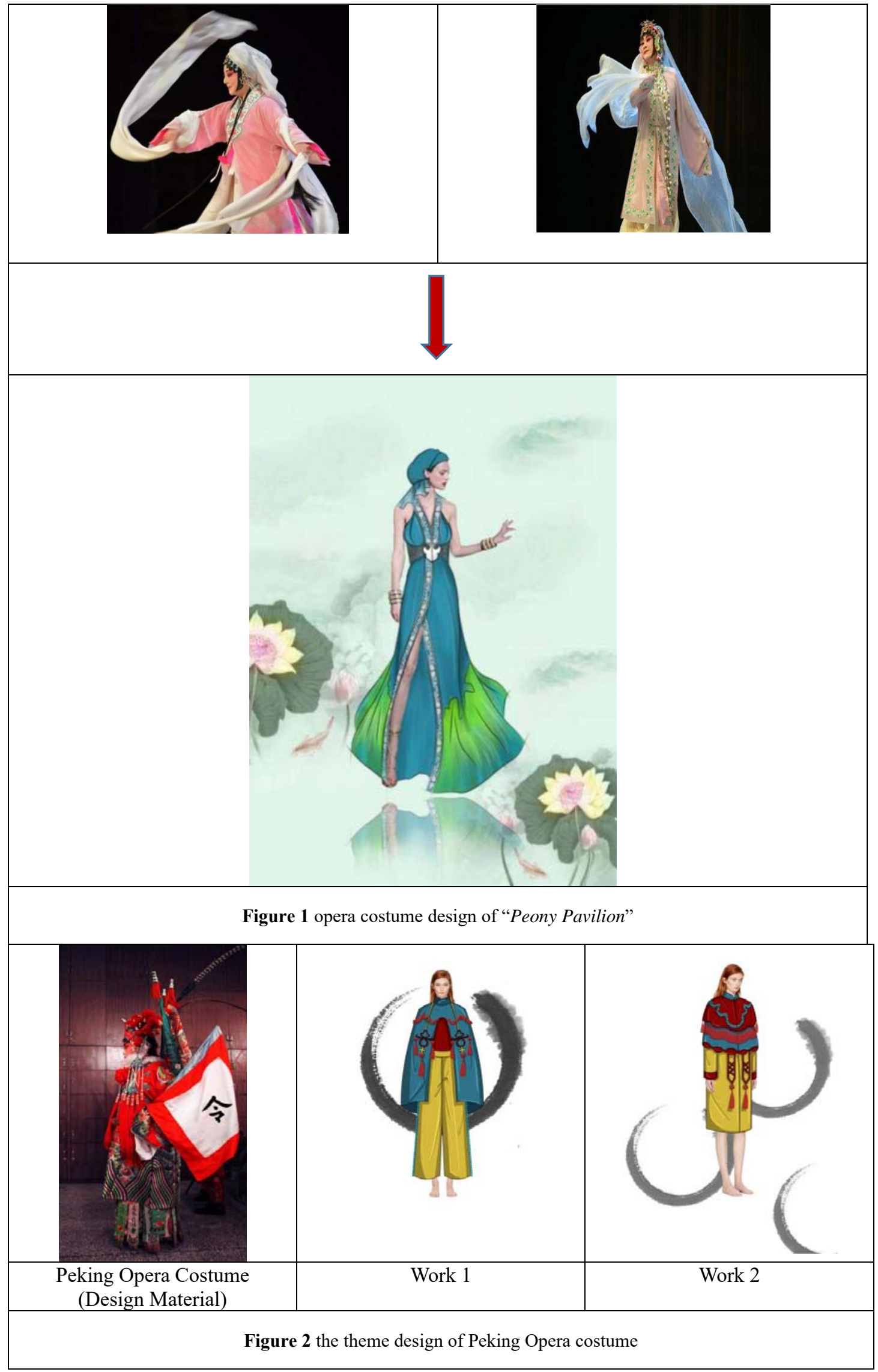

\subsection{The Collection and Application of Opera Costume Colors}

Color is an important element of clothing. For clothing, there is a saying that "Color from far look, style form near look". Clothing color has a feature of strong visual, and different colors give people different visual feelings, with 
different symbolic meanings. For instance, green makes people feel fresh and elegant, with a sense of peace, comfort and growth; red is bold, warm, but with a sense of impatience. Color matching plays an important role in modern clothing design.

Traditional Chinese opera costumes are colorful, and their color matching is different due to various types of plays, roles, plots and so on. For instance, the younger characters such as Xiao Dan (Dan is one of the main characters of Peking Opera, mainly referring to the image of women, Xiao Dan means young women) and Xiao Sheng (Xiao Sheng is one of the roles of traditional opera, which refers to young men), etc., their costumes of traditional Chinese opera mostly use bright colors to reflect the young people's vigorous and passionate. But under the different characteristics of young people, the choice of clothing color will be different. For instance, in the opera "Dream in the Deserted Garden", in order to show Du Liniang's talent and her official identity, her costume color is usually elegant and luxurious. [1]. Costume color in Chinese opera contains the wisdom and emotion of ancient people, and complements the hierarchical system in the plot, the psychological temperament of characters in the opera, the customs and habits of the birthplace of the opera. It is also the source of modern closing color matching by designers. Generally speaking, there are two ways for designers to design the modern costumes: one is to directly copy and use traditional color matching in opera costumes; the other is to refine the traditional color of opera costumes and reconstruct the area of color matching. As shown in Figure 3 , this series of costume colors designed by the designer come from the Peking Opera -- "Mu Guiying Command" of costume colors. The designer did not copy the color relations, but changed the area ratio of traditional costume colors, without losing the traditional charm, and integrating designer's innovation. In the meantime, for designers, the choice of cold tones or warm tones, bright color or dark color, and issues affected by wearing time, occasions and other factors should be taken into account when doing color matching.

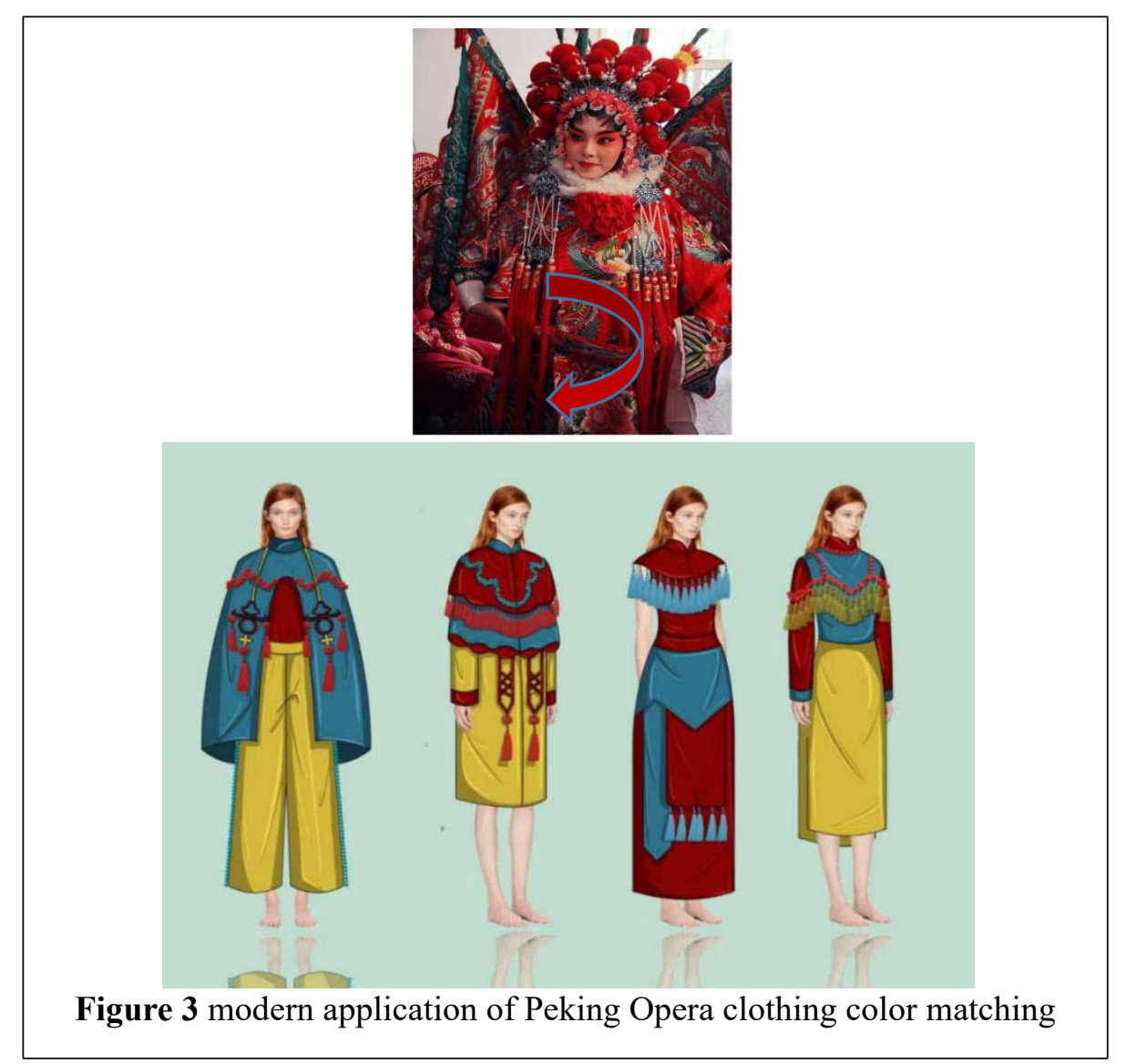

\subsection{Costume Elements of Opera in Costume Design}

In modern fashion design, pattern decoration is the design method that many designers like to adopt. Through the use of embroidery or printing and dyeing of patterns, clothing style visually gives viewers a kind of aesthetic enjoyment.

With the theme of "Sceneries of Time", Shiatzy Chen's 2014 spring/summer womenswear collection deconstructed the facial features of Peking Opera and drew them on the clothes with relatively easy strokes. Only a few lines create a pattern image that conforms to the modern aesthetic, and shows Oriental elements (Figure 4). The design inspiration of MUKZIN 2017 autumn/winter collection went back to the little-known "Maoer Opera" (A troupe or play formerly composed entirely of young actresses) in traditional Peking Opera. In the name of "Maoer", traditional design awakens a new era of women's consciousness. While retaining the 
traditional image of "Maoer Opera", the designer endows the innovation in modeling, reconstructs the modern clothing in the form of pattern, and perfectly deduces the new era aesthetic characteristics of opera clothing (Figure $5)$.

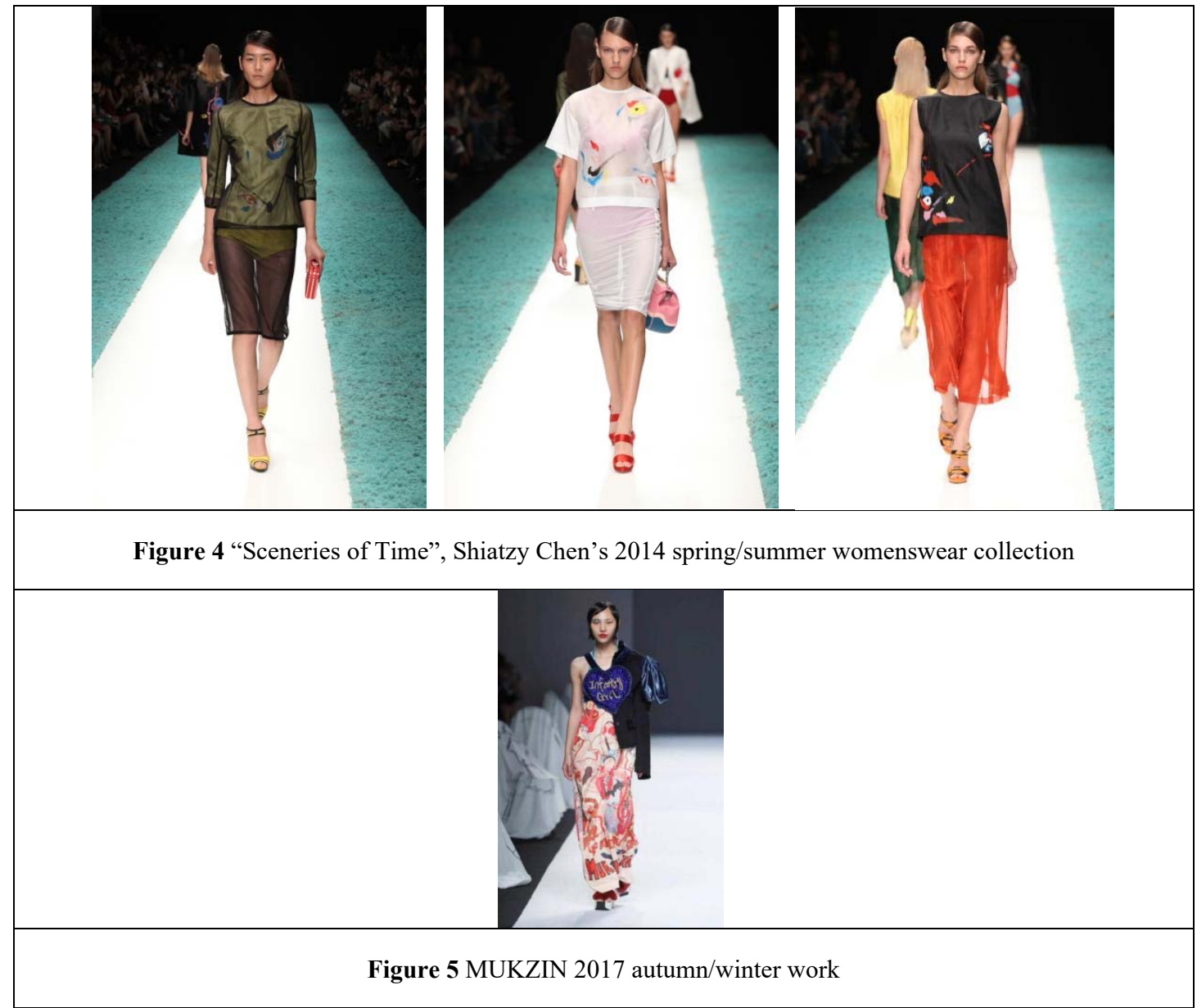

\subsection{Costume Elements of Opera in Costume Accessories}

Accessories are the vital part of costume design. Opera costume elements are often applied in costume design. The term "element" not only refers to style modeling elements, colors, fabrics, etc., but also refers to costume accessories that play a role in setting off opera costume itself, such as helmets, crowns, hats, shoes and so on.

In Valentin Yudashkin's 2013 autumn/winter RTW fashion show works, the costume hat became the inspiration for designers, and they used design methods like modeling simplification, material transformation, color change, etc. to the headdress of autumn and winter works, which not only had the charm of traditional opera costumes, but also kept the modern fashion sense. The combination of costume hats and modern hats has no conflict (Figure 6). In Figure 7, the designer extracts the headscarf of the "Peony Pavilion" costume, retains its modeling and fabric texture, and applies it to the design of modern dress rather than its original color relations and pattern, which is very personalized and also in line with the aesthetic taste of modern consumers. The design of these two series makes the value of opera costumes to be extended and deepened, which shows the reference value and practical significance of design promotion. 



\section{The Application Design Process of Costume Elements in Modern Costume Design}

As a treasure of Chinese traditional culture, opera originated from primitive song and dance, which is a comprehensive stage art with a long history. After the Han, Tang, Song and Jin Dynasties, a relatively complete opera art was formed. It is composed of literature, music, dance, art, martial arts, acrobatics and performing arts, with more than 360 types. However, with the emergence of new concepts and ideas, the development of opera is seriously restricted due to the decrease of audience and the shrinkage of performance market. Therefore, it is urgent to solve the problem of sustainability of opera culture.

Nowadays, in the new situation of advocating national cultural self-confidence, Chinese culture not only should be perceived by people in the traditional way, but also appears in people's daily life in a more diversified form. Thus, modern clothing is the best medium for cultural communication. However, when designers design and apply the elements of opera costumes, what are the steps in the specific process? How to combine the opera costume elements with modern costume design? In view of these problems above and combining many years of teaching experience and practice, the author puts forward the "three steps" in the application process, including the determination of theme, the selection and analysis of inspiration materials, and the extraction and transformation of inspiration elements.

\subsection{Determination of Theme}

When applying opera costume elements in modern costume design, first of all, designers should determine the theme in the form of words, such as Kunqu Opera, Sichuan Opera, Tibetan opera, or something else. Then, collect the pictures according to the theme and establish the database.

\subsection{The Selection and Analysis of the Inspiration Materials}

After the collection of pictures and the establishment of database, the designer should screen the theme data, select what he/she has interested in as the theme inspiration material, and analyze it (by analyzing its history and culture, summarizing its characteristics and value, etc.) to reserve for the next step of design. As shown in Figure 8, the designer chooses Peking Opera as the theme. Under this theme, the designer collects relevant materials, then classifies, selects and analyzes them, and extracts the main elements of Peking Opera Costumes which are headdress, 
armour flags (the four triangular flags, made of silk and embroidered, strapped over the back of a warrior outside of his coat of mail) and facial makeup (a type of painting on the opera actors' faces). Then, the designer chooses facial makeup of Peking Opera as the main element of the design, and displays it with pictures and texts, so that the viewers can understand it at a glance.

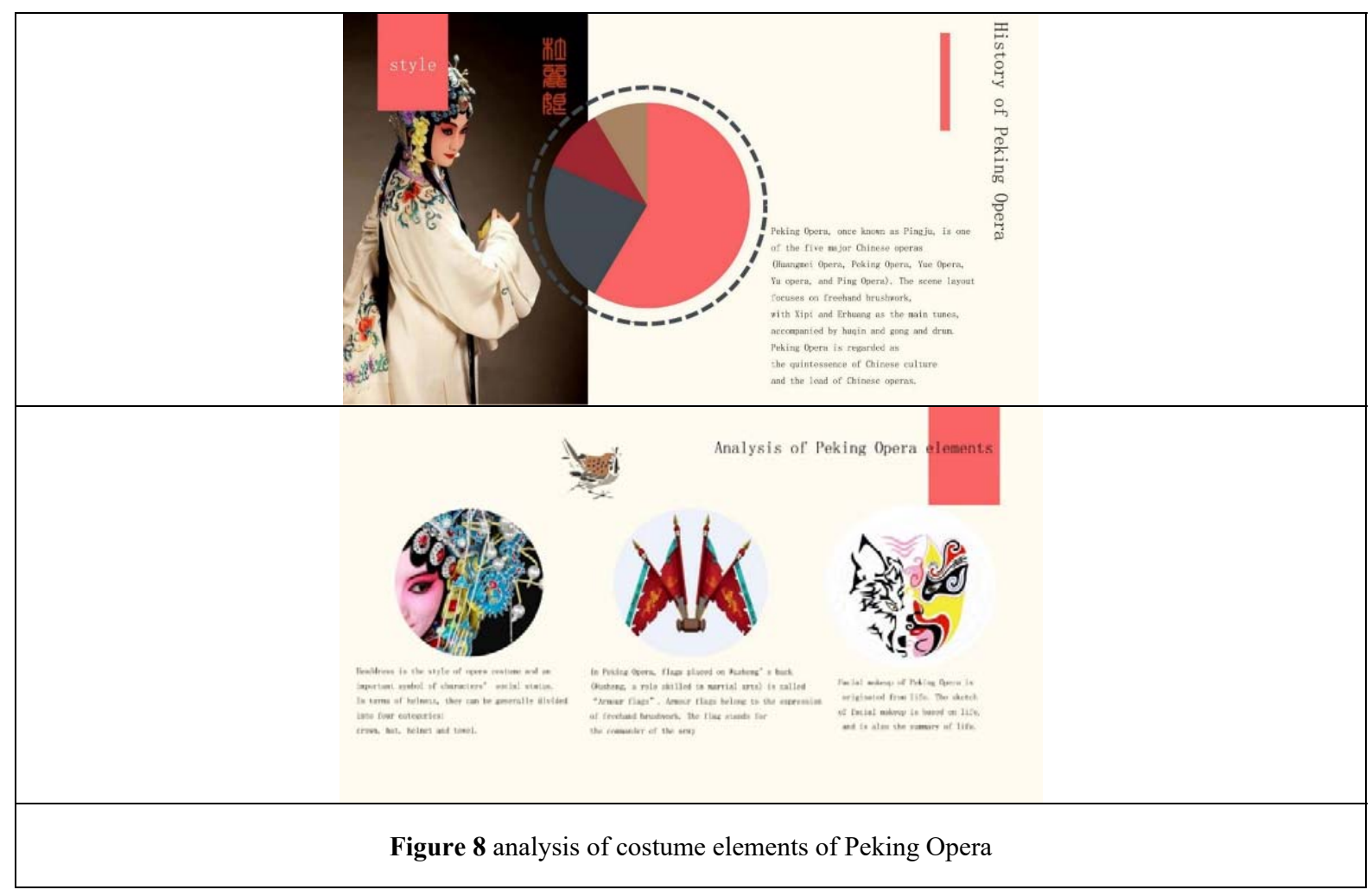

\subsection{Elements Extraction and Application}

After the steps mentioned above, next part will be the elements extraction and application. As shown in Figure 9, under the theme of Peking Opera, the designer extracts the elements of facial makeup (Peking Opera facial makeup, which goes beyond the concept of characters' makeup in opera and sets costume, is part of the costume of Peking Opera) and combines them with modern costume design. The designer adopts the method of patterning the Peking Opera facial makeup to simplify its original shape, remove the original color, and make it integrate with the fabric color. Then, design the layout according to the clothing style, to enlarge or reduce the facial makeup elements, which sets off the clothing style and has unique decoration.

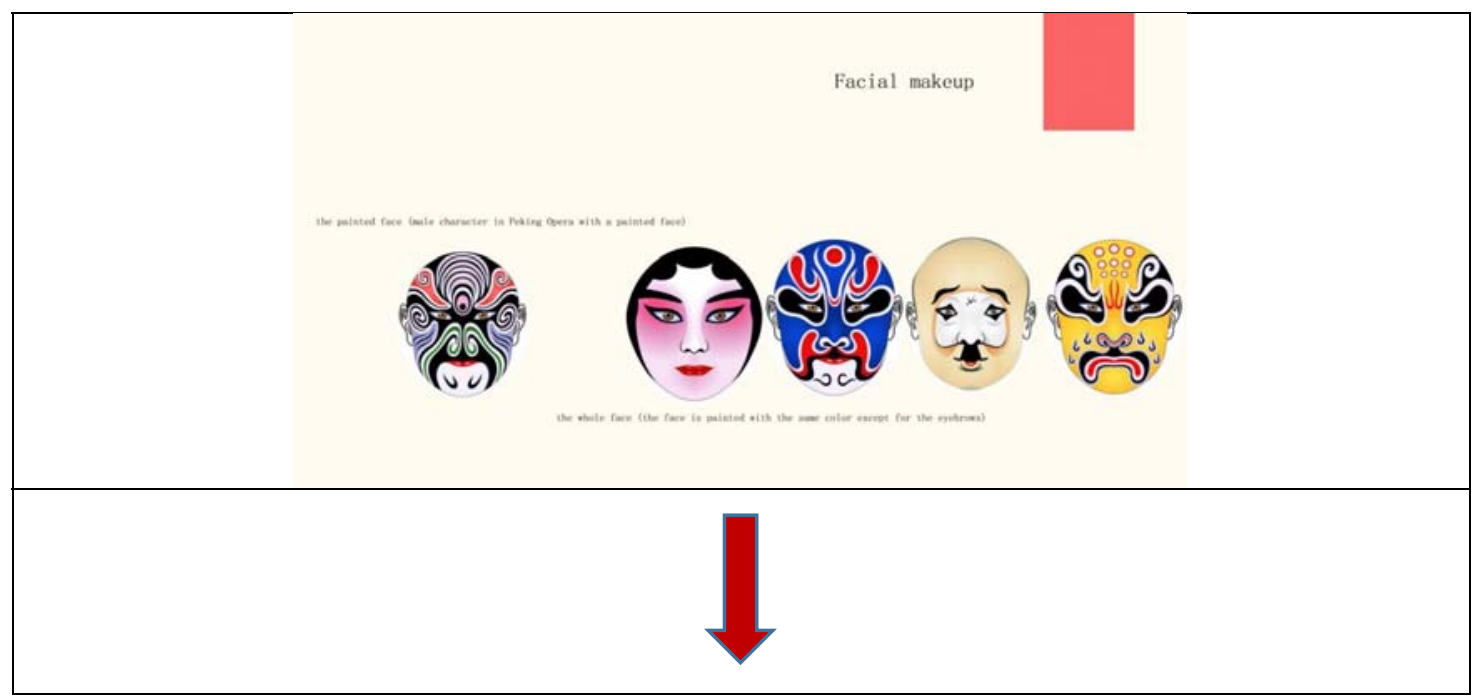




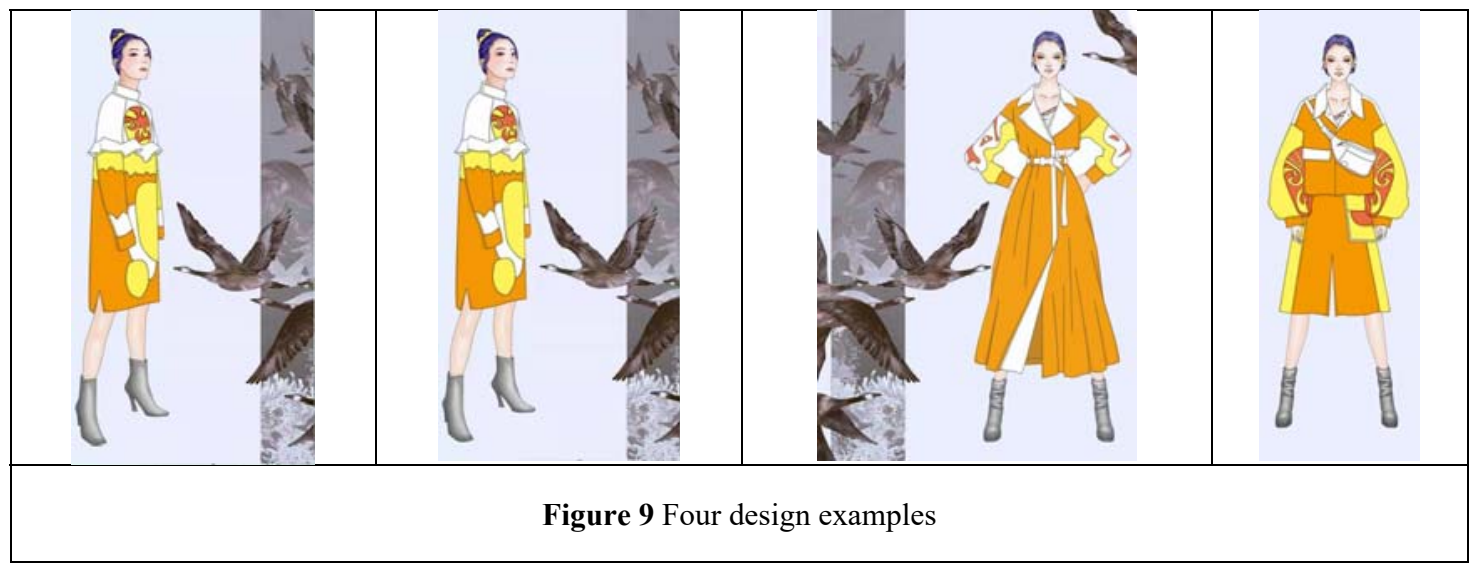

From the perspective of pattern application, the design ingeniously integrates the idea and process, and designs the clothing with the traditional Chinese opera culture in line with the modern aesthetics. It can be seen from the works that the application of opera costume elements in modern costume design is not completed in one go, but in steps. As a designer, we should know what to do and how to complete each step. In the process of modern fashion design, rationality and sensibility are mixed. If designers combine rationality and sensibility skillfully, they will be able to design works accepted by most people.

\section{Conclusion}

In view of the application of opera costume elements in modern costume design, the application of design process and ideas complement each other. Analyzing other designers' works and gaining inspiration from them will be the first step of application design; secondly, designers should make clear each step of design and solve problems they meet during the design process. The "three steps" of design and application proposed in this paper is bound to bring reference to relevant designers. The analysis of traditional opera costume elements in modern costume design is of great significance. It is also of great value for the inheritance of traditional culture and the development of modern costume design.

\section{Reference}

[1] Gao Shanhu. On the overseas communication of Sichuan Opera from the perspective of communication [J]. Journal of Qujing Teachers' College, 2017(4):117-120.

[2] Wang Peixi. On the stage costumes of the Peony Pavilion in Kunqu Opera [J]. Journal of National Academy of Chinese Theatre Arts, 2008, (04):55-59.
[3] Zhou Juan. Floating as duckweed, tough as grass-Brief analysis on the image of Nixi in Zhang Ailing's Concatenate Traps, 2014, (06):79-82.

[4] Qian Xulin. "Chinese style" in modern fashion design $[\mathrm{J}]$. Journal of Clothing Research, 2018(10):416-421.

[5] Wang Qiming, \& Lin Yaoyao. A study on the sleeve style of women's dress in Tang Dynasty [J]. Journal of Clothing Research, 2017(01):61-72.

[6] Li Yufei, \& Liang Huie. Research Status and Trend of Qilu Ceremonial Costumes in Ming Dynasty [J]. Journal of Clothing Research, 2018(044):147-152.

[7] Zhu Wei. The cultural connotation of Beijing Opera Costume [J]. Home Drama, 2016(03):18-19

[8] Zhang Li, \& Cheng Ganlin. The presentation and aesthetic features of opera symbols in Beijing Opera Costume [J]. Xi'an Polytechnic University, 2015(05):631-635.

[9] Tang Xiangning, Xu Liping, Ma Yuqing, Duan Xuwang, Han Chi \& Wu Qiaoyan. Innovative design of silk scarves with Beijing Opera costume elements, [J]. Journal of Silk,2015(09):41-45.

[10] Yu Haiwei. Research on the application of traditional Beijing Opera dress pattern in modern Women's dress design under the market background, [J]. China Market, 2017(36):83-84.

[11] Lin Yanping. A study of costume patterns in traditional Chinese opera, [J]. Melliand China, 2017(08):52-54.

[12] Lin Yanping. Research on costume color culture in Chinese opera, [J]. Melliand China, 2016(04):5255.

[13] Chen Mei. Analysis of the dress form of the traditional opera of Kun Opera, [J]. Donghua University, 2010.

[14] Pan Ting. A study of folk culture in the Peony Pavilion, [J]. Gannan Normal University, 2013. 